\title{
Beta-blocker use associates with lower prevalence of joint pain and lower opioid requirement in people with osteoarthritis
}

Ana M Valdes $\mathrm{PhD}^{1,2}$, Abhishek Abhishek PhD MRCP ${ }^{1}$, Kenneth Muir $\mathrm{PhD}^{3}$, Weiya Zhang $\mathrm{PhD}{ }^{1,2}$, Rose A Maciewicz PhD ${ }^{4}$, Michael Doherty MD FRCP ${ }^{1,2}$

${ }^{1}$ Academic Rheumatology, University of Nottingham, Clinical Sciences Building, Nottingham City Hospital, Nottingham NG5 1PB, UK

${ }^{2}$ Arthritis Research UK Pain Centre, School of Biomedical Sciences, University of Nottingham, Queen's Medical Centre, Nottingham, UK

${ }^{3}$ School of Medicine, University of Manchester, UK

${ }^{4}$ Respiratory, Inflammation, Autoimmunity iMed, AstraZeneca R\&D Cambridge, da Vinci Building, Melbourn Science Park, Cambridge Road, Hertfordshire, SG8 6HB, UK

\section{Correspondence to:}

Ana M Valdes, Academic Rheumatology Clinical Sciences Building, Nottingham City Hospital, Hucknall Road, Nottingham, NG5 1PB, UK

Phone number: +44 (0)115 823 1954; Fax number:+44(0) 1158231757 email: Ana.Valdes@nottingham.ac.uk

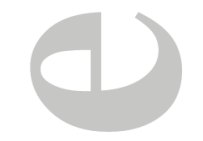

\section{Funding}

This work was supported by a EULAR project grant to AMV (grant 108239) and through the Arthritis Research UK Pain Centre (grant 18769). The GOAL cohort collection was partly funded by AstraZeneca plc. RAM is an employee and owns stock of AstraZeneca plc.

This article has been accepted for publication and undergone full peer review but has not been through the copyediting, typesetting, pagination and proofreading process which may lead to differences between this version and the Version of Record. Please cite this article as an 'Accepted Article', doi: 10.1002/acr.23091 


\section{BRIEF REPORT}

\section{(1)}

\section{Abstract}

Objective: Recent findings suggest that $\beta$-adrenergic blockers have anti-nociceptive properties. The aim of this study was to compare levels of large joint pain between those on adrenergic blockers and those on other antihypertensive medications

Methods: Data from the GOAL study, a secondary care cohort of osteoarthritis (OA), were used. Joint pain was assessed using the Western Ontario and McMaster Universities Arthritis (WOMAC) pain score in 873 individuals who had symptomatic hip and/or knee OA and hypertension, and who were on $\geqslant 1$ prescription antihypertensive medications. The association between adrenergic blocker prescription and a) at least moderate joint pain (WOMAC <75), and b) use of prescription analgesics was examined using binary logistic regression. Analyses were adjusted for age, gender, BMI, knee or hip OA, history of joint replacement (at other joints), anxiety and depression.

Results: Use of $\beta$-adrenergic blockers associated with lower WOMAC pain scores and with a lower prevalence of joint pain after adjustment for demographic variables and comorbidity (adjusted odds ratio $\left(\mathrm{aOR}_{\mathrm{pain}}=0.68(95 \%\right.$ C.I. 0.51-0.92; $\mathrm{p}<0.011)$ ). No associations with pain were observed with use of $\alpha$-blockers $\left(\mathrm{aOR}_{\text {pain }}=0.94(95 \%\right.$ C.I. $\left.0.55-1.58)\right)$ or with any other class of anti-hypertensive medications. Prescription of $\beta$-blockers also associated negatively with opioid use $\left(\mathrm{aOR}_{\text {opioids }}=0.73(95 \% \mathrm{Cl} 0.54-0.98 ; \mathrm{p}<0.037)\right)$ and with use of prescription analgesics in general $\left(a O R_{\text {analgesics }}=0.74(95 \% \mathrm{Cl} 0.56-0.94 ; p<0.032)\right)$.

Conclusion: Use of $\beta$-blockers associates with less joint pain and lower use of opioids and other analgesics in individuals with symptomatic large joint $O A$. This observation needs to be confirmed in other studies.

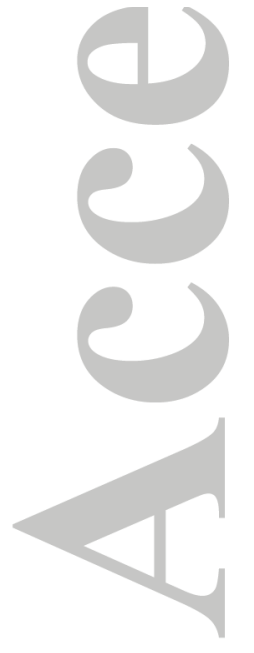


BRIEF REPORT

Key points:

- Animal models and human studies suggest an anti-nociceptive role for beta adrenergic blockers.

- We assessed, in individuals diagnosed with both osteoarthritis and hypertension, whether there were differences in the prevalence of joint pain and analgesic use among those on beta-blockers compared to other antihypertensive medications.

- We found that use of beta blockers is associated with a lower prevalence of joint pain and a lower use of prescription analgesics.

- This finding raises the possibility that this class of drugs may be used as analgesics for joint pain. 


\section{BRIEF REPORT}

\section{(1)}

\section{Introduction}

Hypertension is a common comorbidity in older people and occurs in up to $40 \%$ of individuals with osteoarthritis (OA) [1]. Treatment of joint pain in hypertensive patients is a therapeutic challenge due to the adverse effects of some analgesics especially non-steroidal anti-inflammatory drugs (NSAIDs) on blood pressure [2]. The therapeutic focus to date has been on selecting analgesic medications that do not increase cardiovascular risk for these patients. Identification of anti-hypertensive medication that may reduce the need for analgesic drugs has not been investigated to date.

Adrenergic neurotransmission is an integral part of the pathways that regulate the response to pain and stress [3]. The increase in $\alpha 1$-adrenoceptor expression after nerve and tissue injury plays a role in neuropathic pain syndromes [3] and $\beta 2$-adrenergic receptor modulates the response to morphine via its heterodimerization with one of the splice forms of the mu opioid receptor 1 [4]. An anti-nociceptive effect of $\beta$-blockers has been demonstrated recently in a mouse model of chronic pain [5]. Importantly, both in patients with fibromyalgia and in those with temporomandibular joint disorder the number of painful body sites and selfreported pain severity is significantly lower after beta-blockade when compared to placebo [6]. The clinical implication of these findings is that use of adrenergic receptor antagonists might reduce the prevalence and severity of chronic pain.

Antagonists to $\alpha$ and $\beta$-adrenergic receptors have been used for decades, particularly in the treatment of hypertension. Because hypertension is extremely common among OA patients we hypothesized that joint pain levels will be lower in those whose anti-hypertensive therapy includes $\alpha$ or $\beta$-blockers than in those whose therapy is based on a different molecular pathway, and that this should reduce the requirement for conventional analgesics. We investigated this in a case-control study of $O A$ in which participants underwent radiographic 


\section{BRIEF REPORT}

assessment of both hips and knees and gave extensive questionnaire information on their joint pain, general health, medical diagnoses and use of all prescription drugs including antihypertensive medications [7].

\section{Subjects and methods:}

Genetics of osteoarthritis and lifestyle (GOAL) study. Hip and knee OA cases were recruited from hospital orthopaedic surgery lists in the Nottinghamshire area between 2002 and 2006 as previously described [7]. Approval for recruitment was obtained from the research ethics committees of Nottingham City Hospital and North Nottinghamshire. Standardised pelvis and knee radiographs (weight-bearing tibiofemoral and $30^{\circ}$ flexion skyline views) were obtained. Individuals who had symptomatic and radiographic knee OA defined as Kellgren and Lawrence grade $\geqslant 2[8]$ at either the tibiofemoral or patellofemoral compartment in either knee or who had radiographic hip OA (defined as Croft grade $\geqslant 3$ ) [9] were included as OA cases, regardless of whether or not they had already undergone a total joint replacement (TJR) Individuals assessed post TJR were assessed on average 2.2 years post-surgery $(S D=2.4$ years $)$. All included participants had hip or knee pain assessed using the Western Ontario and McMaster Universities Arthritis (WOMAC) score. [10]

Hypertension classification: All participants underwent a clinical examination and detailed medical questionnaire. Only participants who reported physician diagnosed hypertension and were on at least one prescription antihypertensive medication were included in the analyses.

Other comorbidities: Participants were asked whether they had been diagnosed by a physician with comorbidities including asthma, chronic obstructive pulmonary disease, anxiety and depression.

Use of medication: A trained research nurse assessed use of prescription medications by participants including anti-hypertensive and analgesic medications. For this, participants were asked to show their complete GP prescription or all prescription and OTC medications 


\section{BRIEF REPORT}

to the nurse. . Participants also self-reported the duration of use for each medication. The names of medications were reviewed by $A V$ and $A A$ to identify the drugs of interest.

Anti-hypertensive medications were classified as follows:

a-adrenergic blocker: doxazosin

$\beta$-adrenergic blockers: acebutolol, atenolol, bisoprolol, celiprolol co-tenidone, metoprolol, nebivolol, propranolol, sotalol, timolol (excluding ocular use for glaucoma)

- ACE inhibitors: quinapril, enalapril, lisinopril, rampiril, perindopril, trandolapril.

- Angiotensin II receptor antagonists (ARBs): losartan, irbesartan, olmesartan, valsartan, telmisartan.

- calcium channel blockers (CCBs): amlodipine, felodipine, lercanidipine, nifedipine

- diuretics: acetazolamide, bendrofluazide, furosemide, indapamide

Prescription analgesic medications were classified as follows:

- Opioids: buprenorphine, co-codamol, co-proxamol, codeine, dihydrocodeine, codydramol, solpadol, tramadol.

NSAIDs: arthrotec, celecoxib, diclofenac, etodolac, etoricoxib, indomethacin, meloxicam, nabumetone, rofecoxib

other prescription drugs for pain: amitryptiline, gabapentin, pregabalin

Statistical analysis: The WOMAC pain subscale score is not normally distributed [11]. Therefore two approaches were used: (1) we defined joint pain as present using the cut-off of WOMAC score that has been used by others for as being moderate joint pain [11], defined as a WOMAC score $<75$ on a $0-100$ scale $(100=$ no pain) as the primary outcome in logistic regression analyses adjusting for age, sex BMI, history of TJR, joint affected by OA (hip, knee or both) and self-reported anxiety and depression. (2) we log transformed the WOMAC pain scores and used is as the outcome in linear regressions adjusting for the covariates as above. Logistic regression, adjusted for covariates as above was used to examine the association between adrenergic receptor blocker prescription and analgesic prescription. All statistical analyses were carried out using the $\mathrm{R}$ statistical package (https://cran.rproject.org/) and $p<0.05$ was set as statistically significant. 


\section{BRIEF REPORT}

\section{Results}

The descriptive characteristics of the study participants according to their beta-blocker use are presented in Table 1. Overall there were significant differences in the average pain scores and in the prevalence of joint pain defined as WOMAC $<75$. The number and type of anti-hypertensive medications taken by the two groups was significantly different as was the prevalence of asthma, which reflects prescribing practices for hypertension. [12]

After adjusting for age, gender, BMI, use of $\beta$-blockers was associated with a lower prevalence of joint pain $\left(\mathrm{OR}_{\text {joint_pain }}=0.70 ; 95 \% \mathrm{Cl} 0.52-0.93\right.$; Figure $\left.1 \mathrm{~A}\right)$ This remained significantafter further adjustment for knee OA, hip OA, history of TJR, anxiety and depression, ( odds ratio adjOR $\mathrm{R}_{\text {joint_pain }}=0.68 ; 95 \%$ C.I. 0.51-0.91). A similar result was seen with use of adrenergic blockers in general $\left(\mathrm{OR}_{\text {joint_pain }}=\mathrm{OR}=0.70 ; 95 \% \mathrm{Cl} 0.52-0.93 ;\right)$ and no association was seen with use of $\alpha$-blockers (Figure 1A). The number of years of being on $\beta$-blockers was also associated with a reduced risk of joint pain (OR per one year increase in duration of use of $0.96(95 \% \mathrm{Cl} 0.93,0.99 ; p<0.004)$. The association between use of $\beta-$ blockers and joint pain was similar in indivdiuals with a history of joint replacement but ongoing symptomatic $\mathrm{OA}$ at un-operated joints $\left(\mathrm{OR}_{\text {joint_pain }}=0.66 ; 95 \%\right.$ C.I. 0.26-0.93) and those who had not undergone arthroplasty $\left(\mathrm{OR}_{\text {joint_pain }}=0.75\right.$; 95\%C.I. 0.44-1.27).

Prescription of $\beta$-blockers was further associated with lower rate of prescription of analgesics $\left(\mathrm{OR}_{\text {analgesics }}=0.74 ; 95 \%\right.$ C.I.0.56-0.97). This association was attributable largely to prescription of opioids $\left(\mathrm{OR}_{\mathrm{opioids}}=0.73 ; 95 \% \mathrm{Cl}\right.$ 0.54-0.98) (Figure 1B). Importantly, no other class of anti-hypertensives showed any association with joint pain (Figure 1C) or with prescription of analgesics (Figure 1D).

Individuals on $\beta$-blockers were taking a higher number of antihypertensive medications than those not on $\beta$-blockers (Table 1). We therefore explored whether this could be a confounding factor. However, the number of anti-hypertensive medications did not associate with the prevalence of joint pain $\left(\mathrm{OR}_{\text {joint_pain }}=0.92(95 \%\right.$ C.I. $0.70-1.21)$ and adjusting for this 


\section{BRIEF REPORT}

potential confounder did not change the association between $\beta$-blockers and prevalent joint pain $\mathrm{OR}_{\text {joint_pain }}=0.69(95 \% \mathrm{Cl} 0.51-0.94)$.

Another significant difference between the two groups was the presence of self-reported asthma or chronic obstructive pulmonary disease (COPD). Individuals with asthma or COPD in this cohort had a higher prevalence of joint pain $(54 \%$ in those with self-reported asthma or COPD vs $40 \%$ in those without). Use of $\beta$-blockers is not usually recommended in these conditions as it may worsen bronchoconstriction [12], so we assessed whether the association between $\beta$-blockers and pain could be confounded by asthma/COPD. However, after excluding participants with asthma/COPD from the analysis the association between $\beta$ blocker prescription and WOMAC pain remained significant with a similar effect size $\left(\mathrm{OR}_{\text {joint_pain }}=0.73(95 \%\right.$ C.I. 0.54-0.99);

Finally to test the robustness of the above approach we used the log transformed WOMAC pain scores as the outcome in linear regressions (Table 2). These analyses confirmed that beta blocker use is associated with better WOMAC pain scores after adjusting for potential confounders, and that the association is essentially the same in men and women and in individuals with or without a history of TJR at other joints. No association between WOMAC scores and other forms of anti-hypertensive therapy were found (Table 2).

\section{Discussion}

To our knowledge this is the first study to show that use of $\beta$-adrenergic receptor antagonists for hypertension in middle-aged and older adults with OA associates with lower levels of joint pain and lower use of opioid analgesics.

Possible confounding was examined in this study. Because $\beta$-blockers act by preventing release of adrenaline and noradrenaline it is possible that the analgesic benefit could be mediated by reducing anxiety which is strongly associated with pain. However, adjusting for anxiety and depression did not alter the results. Possible confounding by indication in individuals with asthma or COPD was also examined, but after excluding people with these 


\section{BRIEF REPORT}

diagnoses the associations remained. Therefore, these data support a direct association between $\beta$-blockers and lower levels of joint pain in this study population. This is consistent with recent experiments in murine models of inflammatory and chronic pain showing significant anti-nociceptive properties for bupranolol [5] and with the analgesic effect of propranolol versus placebo in patients with fibromyalgia or with temporomandibular joint disorder [6].

There are a number of limitations to this study. Firstly, this is a cross-sectional observation, the causality between beta-blockers and joint pain has yet to be established. Secondly, the study population was derived from a hospital based case control study for large joint OA, many of whom had already undergone arthroplasty at another joint site even though they had still ongoing symptomatic OA at other joints, hence selection bias cannot be avoided. Thirdly, this is only an observational study, potential confounding factors, especially those unknown cannot be fully controlled. More robust method such as randomised controlled trial is required to confirm the findings. In addition, the number of years that individuals have been on antihypertensive medication was self-reported, we have no data on adherence to such medication, for individuals with hypertension and other indications for beta blocker prescriptions we cannot be sure that beta-blocker use was for hypertension,. Moreover, this study focussed on people with knee or hip OA-related pain as their most significant regional pain problem but we did not evaluate which joints were responsible for the pain and we cannot determine from our data whether the pain reported in those who had undergone TJR is predominantly persistent post-surgical pain or pain from the un-operated OA joints. Therefore, further studies are required to address these caveats and to determine the generalisability of the data.

Nevertheless, these results might raise some future research questions for the treatment of hypertension in individuals with joint pain. Current guidance from both NICE in the UK and the JNC VIII committee in the US state that $\beta$-blockers should no longer be preferred as an initial therapy for routine hypertension and should be used only when there is a compelling 


\section{BRIEF REPORT}

indication other than BP control (e.g. angina or chronic heart failure)[13-14]. If confirmed in randomised controlled trials, the data presented here could suggest that in people with chronic joint pain $\beta$-blockers may be considered as part of their anti-hypertensive regimen. More importantly, our results point to an anti-nociceptive value of $\beta$-blockers for joint pain which deserves further investigation in clinical studies.
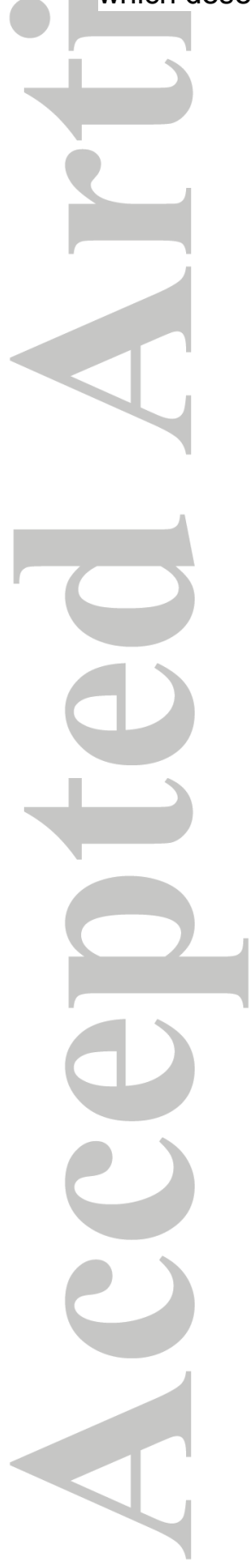


\section{BRIEF REPORT}

\section{References}

1. Verdecchia P, Angeli F, Mazzotta G, Martire P, Garofoli M, Gentile G, Reboldi G. Treatment strategies for osteoarthritis patients with pain and hypertension. Ther Adv Musculoskelet Dis. 2010;2(4):229-40.

2. Mackenzie IS, MacDonald TM. Treatment of osteoarthritis in hypertensive patients. Expert Opin Pharmacother. 2010;11(3):393-403.

3. Drummond PD. Neuronal changes resulting in up-regulation of alpha-1 adrenoceptors after peripheral nerve injury. Neural Regen Res. 2014 ;9(14):1337-40

4. Samoshkin A, Convertino M, Viet CT, Wieskopf JS, Kambur O, Marcovitz J et al Structural and functional interactions between six-transmembrane $\mu$-opioid receptors and $\beta 2$-adrenoreceptors modulate opioid signaling. Sci Rep. $2015 ; 5: 18198$.

5. Martin LJ, Piltonen MH, Gauthier J, Convertino M, Acland EL, Dokholyan NV, et al Differences in the Antinociceptive Effects and Binding Properties of Propranolol and Bupranolol Enantiomers. J Pain. 2015;16(12):1321-33.

6. Light KC, Bragdon EE, Grewen KM, Brownley KA, Girdler SS, Maixner W. Adrenergic dysregulation and pain with and without acute beta-blockade in women with fibromyalgia and temporomandibular disorder. J Pain. 2009;10:542-52

7. Valdes AM, McWilliams D, Arden NK, Doherty SA, Wheeler M, Muir KR, et al. Involvement of different risk factors in clinically severe large joint osteoarthritis according to the presence of hand interphalangeal nodes. Arthritis Rheum. 2010;62(9):2688-95

8. Kellgren JH, Lawrence, J.S. Radiological Assessment of Osteo-Arthrosis. Annals of the Rheumatic Diseases. 1957;16:494-502.

9. Croft P, Cooper, C, Wickham, C, Coggon, D. Defining osteoarthritis of the hip for epidemiologic studies. American Journal of Epidemiology. 1990;132(3):514-22.

10. Bellamy N, Buchanan WW, Goldsmith $\mathrm{CH}$, Campbell J,Stitt LW. Validation study of womac: A health status instrument for measuring clinically important patient relevant outcomes to antirheumatic drug therapy in patients with osteoarthritis of the hip or knee. J Rheumatol 1988; 15(12): 1833-1840

11. Wylde V, Hewlett S, Learmonth ID, Dieppe P. Persistent pain after joint replacement: prevalence, sensory qualities, and postoperative determinants. Pain. 2011;152(3):56672.

12. Arboe B, Ulrik CS. Beta-blockers: friend or foe in asthma? Int J Gen Med. 2013 ;6:54955.

13. Krause $\mathrm{T}$, Lovibond $\mathrm{K}$, Caulfield M, McCormack $\mathrm{T}$, Williams $\mathrm{B}$ on behalf of the Guideline Development Group. Management of hypertension: summary of NICE guidance. BMJ 2011;343:d4891.

14. James PA, Oparil S, Carter BL, Cushman WC, Dennison-Himmelfarb C, Handler J, et al 2014 evidence-based guideline for the management of high blood pressure in 


\section{BRIEF REPORT}

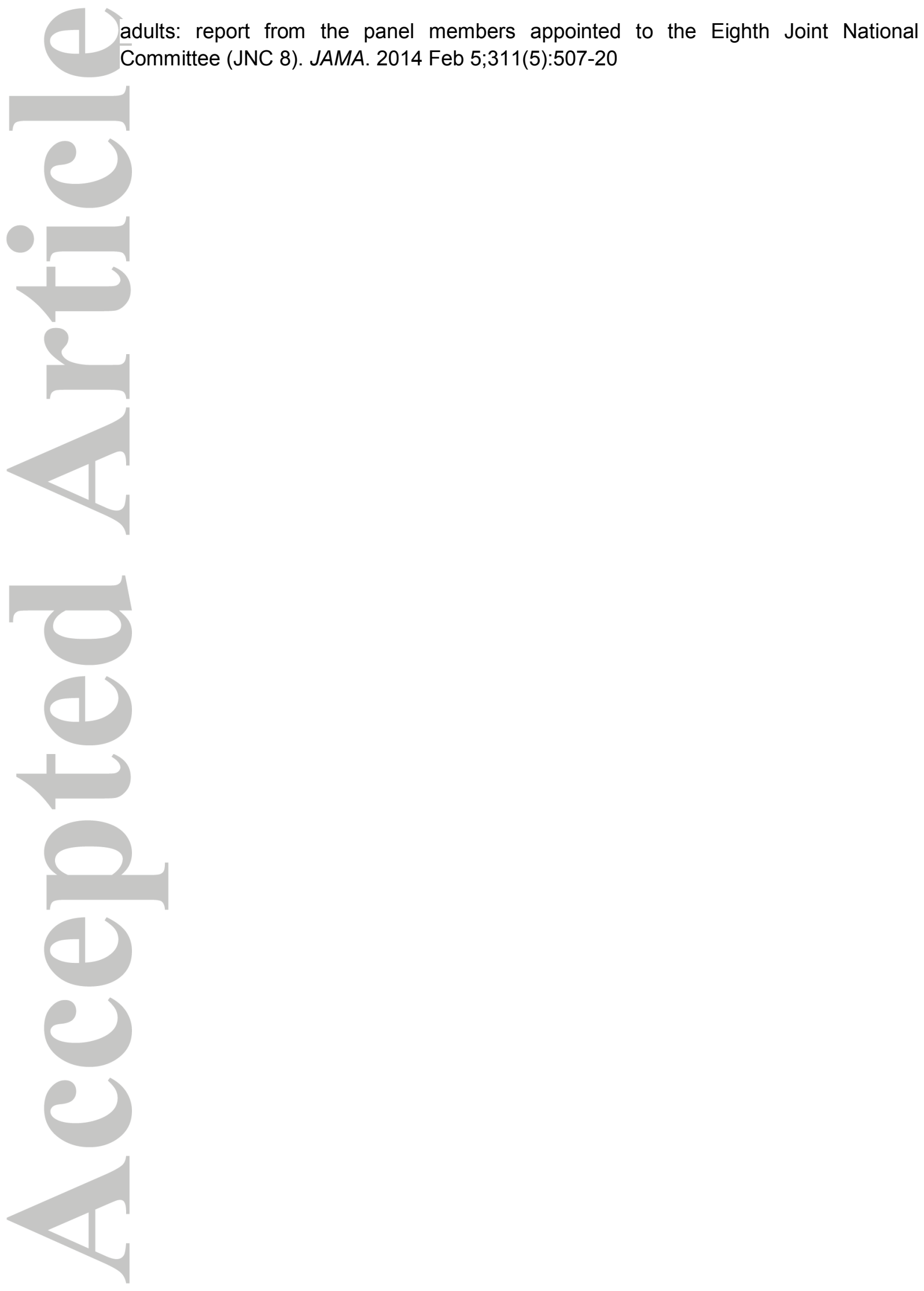

John Wiley \& Sons, Inc.

This article is protected by copyright. All rights reserved. 


\section{BRIEF REPORT}

\section{Table 1. Descriptive characteristics of study participants from a cohort of OA}

\begin{tabular}{|c|c|c|c|}
\hline trait & $\begin{array}{c}\text { not on beta } \\
\text { blockers }\end{array}$ & $\begin{array}{c}\text { beta blocker } \\
\text { users }^{(1)}\end{array}$ & $p$-value \\
\hline Number of participants & 526 & 347 & \\
\hline Women & $46.60 \%$ & $45.00 \%$ & 0.62 \\
\hline Hypertension & $100 \%$ & $100 \%$ & $N / A$ \\
\hline Age years mean (SD) & $69.2(6.8)$ & $69.6(6.4)$ & 0.79 \\
\hline $\mathrm{BMI} \mathrm{kg} / \mathrm{m}^{2}$ mean $(\mathrm{SD})$ & $30.7(5.2)$ & $30.9(5.6)$ & 0.58 \\
\hline hip OA \% & $47.80 \%$ & $53.80 \%$ & 0.1 \\
\hline Both knee and hip OA \% & $41.44 \%$ & $43.80 \%$ & 0.49 \\
\hline $\begin{array}{l}\text { knee K/L radiographic grade } \\
\text { (proportion with grades } 2-3-4 \text { ) } \\
\text { (2) }\end{array}$ & $0.21 / 0.56 / 0.23$ & $00.17 / 0.65 / 0.18$ & 0.26 \\
\hline $\begin{array}{l}\text { Croft hip radiographic grade } \\
{\text { (proportion grades } 3-4-5)^{(2)}}\end{array}$ & $0.28 / 0.52 / 0.19$ & $0.24 / 0.60 / 0.16$ & 0.47 \\
\hline post $T J R^{(3)}$ & $65.78 \%$ & $70.32 \%$ & 0.161 \\
\hline Anxiety & $13.50 \%$ & $12.10 \%$ & 0.54 \\
\hline Depression & $20.70 \%$ & $18.73 \%$ & 0.47 \\
\hline Asthma / COPD & $20.72 \%$ & $5.76 \%$ & $<0.0001$ \\
\hline $\begin{array}{l}\text { WOMAC pain score } \\
(0-100,100=\text { no pain }) \\
\text { mean (SD) }\end{array}$ & $74.6(24.8)$ & $78.9(22.7)$ & 0.0106 \\
\hline Median (range) & $80(10-100)$ & $85(15-100)$ & \\
\hline $\begin{array}{l}\text { moderate } \\
(\text { WOMAC }<75)\end{array}$ & $42.20 \%$ & $34.00 \%$ & 0.015 \\
\hline $\begin{array}{l}\text { number of anti-hypertensive } \\
\text { drugs taken mean (SD) }\end{array}$ & $1.41(0.58)$ & $1.89(0.80)$ & $<0.0001$ \\
\hline a-blocker & $9.50 \%$ & $5.80 \%$ & 0.069 \\
\hline$\beta$-blockers & $0.00 \%$ & $100.00 \%$ & $N / A$ \\
\hline $\begin{array}{l}\text { years on } \beta \text {-blockers mean } \\
\text { (SD) }\end{array}$ & & $6.9(6.6)$ & N/A \\
\hline ACE inhibitors & $37.20 \%$ & $21.90 \%$ & $<0.0001$ \\
\hline $\begin{array}{l}\text { angiotensin II } \quad \text { receptor } \\
\text { antagonist }\end{array}$ & $7.20 \%$ & $10.10 \%$ & 0.13 \\
\hline calcium channel blockers & $31.90 \%$ & $16.70 \%$ & $<0.0001$ \\
\hline diuretics & $55.1 \%$ & $35.4 \%$ & $<0.0001$ \\
\hline & & & \\
\hline opioids & $35.40 \%$ & $28.50 \%$ & 0.035 \\
\hline NSAIDs & $19.60 \%$ & $17.60 \%$ & 0.46 \\
\hline $\begin{array}{l}\text { other prescription drugs for } \\
\text { pain }\end{array}$ & $4.60 \%$ & $3.40 \%$ & 0.42 \\
\hline
\end{tabular}

${ }^{(1)} \beta$-blockers included =acebutolol, atenolol, bisoprolol, celiprolol co-tenidone, metoprolol, nebivolol, propranolol, sotalol, timolol, excluding ocular ${ }^{(2)} \mathrm{K} / \mathrm{L}$ grade only for individuals with a diagnosis of knee $\mathrm{OA}$, Croft grade for individuals with a diagnosis of hip OA, refers to unoperated joints. ${ }^{(3)}$ post TJR= post total joint replacement 


\section{BRIEF REPORT}

Table 2. Association, expressed as linear regression coefficient (beta) and $95 \%$ confidence intervals, between use of anti-hypertensive medication and WOMAC pain scores in individuals diagnosed with hip or knee OA

\begin{tabular}{|c|c|c|c|c|c|}
\hline predictor variable & adjusted for & subset & beta & $95 \% \mathrm{Cl}$ & p-value \\
\hline use of $\beta$-blockers & age sex BMl & all & 0.033 & $(0.010-0.056)$ & 0.0058 \\
\hline use of $\beta$-blockers & $\begin{array}{l}\text { age sex BMI, num. anti } \\
\text { hypertensive meds, } \\
\text { history of TJR, anxiety, } \\
\text { depression, type of } \\
\text { joints affected (hip, } \\
\text { knee, both) }\end{array}$ & all & 0.033 & $(0.009-0.057)$ & 0.0072 \\
\hline f $\beta$-blockers & $\begin{array}{c}\text { as above }+ \\
\text { asthma/COPD }\end{array}$ & all & 0.029 & $(0.005-0.053)$ & 0.0171 \\
\hline of $\beta$-blockers & age BMI & male & 0.030 & $(0.001-0.060)$ & 0.0461 \\
\hline use of $\beta$-blockers & age BMI & female & 0.033 & $(-0.004-0.069)$ & 0.0808 \\
\hline use of $\beta$-blockers & age sex $\mathrm{BMI}$ & no history of TJR & 0.042 & $(-0.004-0.088)$ & 0.0765 \\
\hline use of $\beta$-blockers & age sex BMI & history of TJR & 0.026 & $(0.001-0.051)$ & 0.0421 \\
\hline years on $\beta$-blockers & age sex $\mathrm{BMI}$ & all & 0.003 & $(0.001-0.005)$ & 0.0071 \\
\hline use of CCBs & age sex BMl & all & -0.003 & $(-0.029-0.024)$ & 0.85 \\
\hline use of ARBs & age sex BMI & all & 0.029 & $(-0.013-0.071)$ & 0.18 \\
\hline use of $A C E$ inhibitors & age sex BMI & all & 0.003 & $(-0.022-0.028)$ & 0.84 \\
\hline use of diuretics & age sex BMI & all & -0.008 & $(-0.031-0.016)$ & 0.53 \\
\hline
\end{tabular}

14

John Wiley \& Sons, Inc.

This article is protected by copyright. All rights reserved. 


\section{BRIEF REPORT}

Figure 1. (A) Association between use of adrenergic receptor blockers and prevalence of joint pain defined as WOMAC pain scores $<75$ (B) Association between use of $\beta$-blockers and use of prescription analgesic medication. (C) Association between use of other antihypertensive medication and prevalence of joint pain. (D) Association between use of antihypertensive medication and use of prescription analgesic medication.
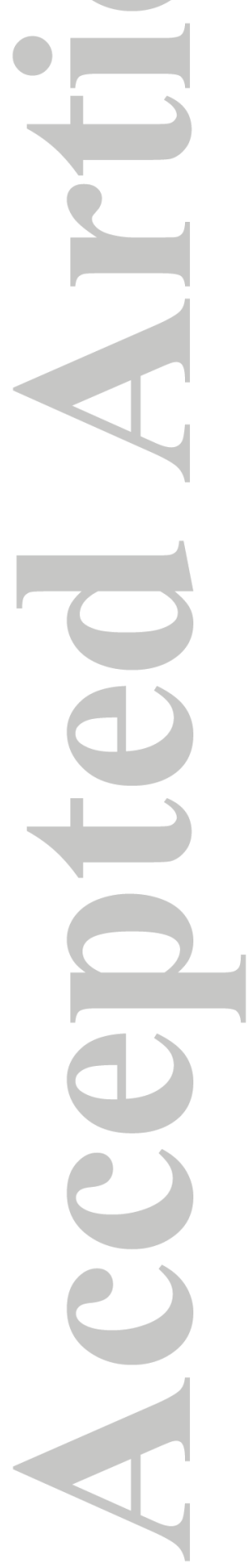
A

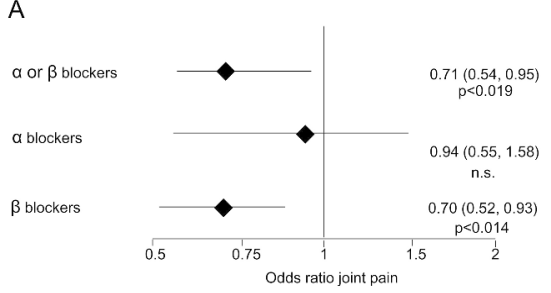

C

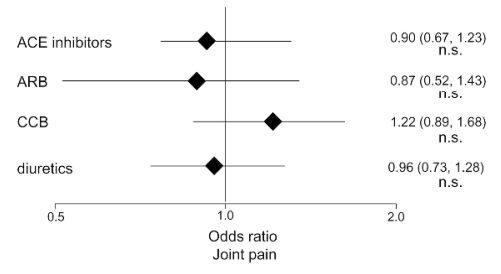

B

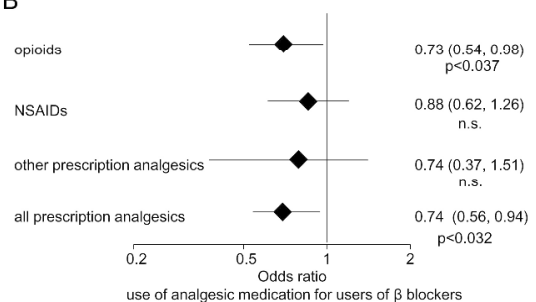

D

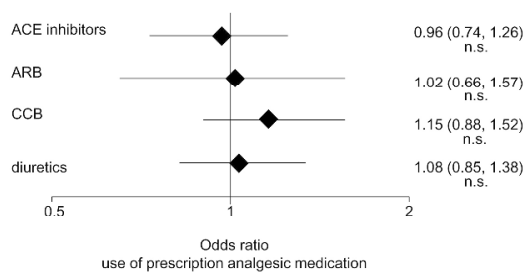

Figure 1. (A) Association between use of adrenergic receptor blockers and prevalence of joint pain defined as WOMAC pain scores $<75$ (B) Association between use of $\beta$-blockers and use of prescription analgesic medication. (C) Association between use of other anti-hypertensive medication and prevalence of joint pain. (D) Association between use of anti-hypertensive medication and use of prescription analgesic medication.

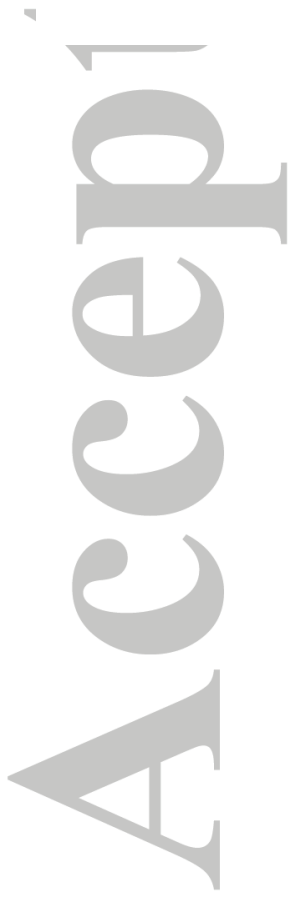

$368 \times 259 \mathrm{~mm}(300 \times 300 \mathrm{DPI})$

John Wiley \& Sons, Inc.

This article is protected by copyright. All rights reserved. 